\title{
Correction to: Photosynthetic activity and photoprotection in green and red leaves of the seagrasses, Halophila ovalis and Cymodocea rotundata: implications for the photoprotective role of anthocyanin
}

\author{
Pimchanok Buapet $^{1,2}$ (D) Fonthip Makkliang ${ }^{3} \cdot$ Chongdee Thammakhet-Buranachai $^{3}$
}

Published online: 23 October 2017

(C) Springer-Verlag GmbH Germany 2017

Correction to: Mar Biol (2017) 164:182

DOI 10.1007/s00227-017-3215-9

Unfortunately, the legend of Fig. 2 was missing in the original publication. The Figure is presented with its legend here.

The online version of the original article can be found under doi:10.1007/s00227-017-3215-9.

Pimchanok Buapet

pimchanok.b@psu.ac.th

1 Plant Physiology Laboratory, Department of Biology,

Faculty of Science, Prince of Songkla University, Hat Yai,

Songkhla, Thailand

2 Coastal Oceanography and Climate Change Research Center, Prince of Songkla University, Hat Yai, Songkhla, Thailand

3 Trace Analysis and Biosensor Research Center, Department of Chemistry, Faculty of Science, Prince of Songkla University, Hat Yai, Songkhla, Thailand 

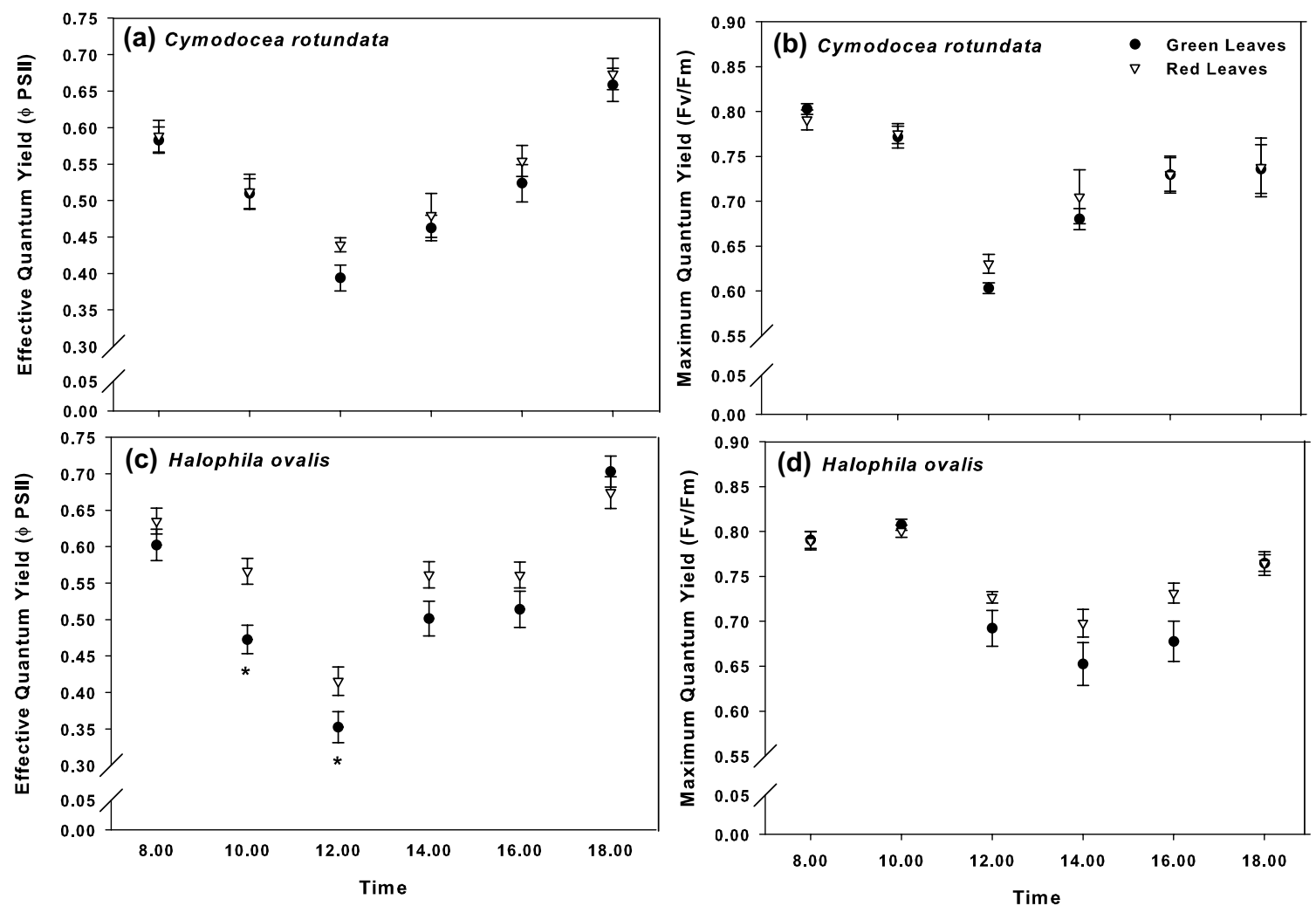

Fig. 2 Diurnal variation in the effective quantum yield $(\mathbf{a}, \mathbf{c})$ and the maximum quantum yield $(\mathbf{b}, \mathbf{d})$ of Cymodocea rotundata and Halophila ovalis. Error bars show standard error, $n=45-52$. Asterisk indicates significant difference between green and red leaves (LSD test, $p<0.05$ ) 